\title{
A NOVEL ROTATING WHEEL MAGNETORHEOLOGICAL FINISHING PROCESS FOR EXTERNAL CYLINDRICAL WORKPIECES
}

\section{GAGANDEEP SINGH $^{1} \&$ ARVIND JAYANT ${ }^{2}$}

${ }^{I}$ Research Scholar, Department of Mechanical Engineering, SantLongowal Institute of Engineering \&Technology, Longowal, Sangrur, Punjab - 148106, India

${ }^{2}$ Professor, Department of Mechanical Engineering, SantLongowal Institute of Engineering \& Technology, Longowal, Sangrur, Punjab - 148106, India

\begin{abstract}
The recent rise in the demand for high precision, close tolerances, and super surface finish quality of components and part assembly modules in the competitive manufacturing industrial environment for the enhanced working life and functional requirements of machines at a global level. A new rotating wheel based magnetorheological process is designed and developed to fine finish the external cylindrical surfaces of soft as well as hard materials. This method is based on the operating concept of the cylindrical grinding system, except that the hard bounded abrasive wheel is replaced with the electromagnet wheel which is capable of generating the regulated magnetic field in the developed process. Due to the generated magnetic field effect, the CIP's particles in the magnetorheological fluid stick-on the wheel and tightly hold the abrasive particles. The fine finishing operation is performed with the help of flexible brushes created by the magnetorheological fluid. A significant range of high precision external cylindrical surface applications can be found in automotive, manufacturing, aerospace, valve \& die industries. In the present study, mild steel cylindrical workpiece is used for experimentation purposes. The surface roughness values $\mathrm{Ra}, \mathrm{Rq}, \mathrm{Rz}$ are reduced to 41.17\%, 44.62\%, 46.45\% in 75 minutes of finishing time with rotating wheel based magnetorheological finishing process. The overall results indicate that the new rotating wheel based magnetorheological process is feasible and capable enough to provide fine finishing operation to the external cylindrical surfaces of soft materials as well as hard materials.
\end{abstract}

KEYWORDS: Magnetorheological Finishing; Surface Roughness; MR Fluid; External Cylindrical Surfaces

Received: Jun 10, 2020; Accepted: Jun 30, 2020; Published: Aug 03, 2020; Paper Id.: IJMPERDJUN2020596

\section{INTRODUCTION}

Nowadays, industries focused on accuracy and precision in manufacturing for a better quality product. The surface quality of the product is achieved by reducing the surface roughness of the product. Surface roughness directly affects the fit, functioning, and life cycle of the high strength applications [1]. To achieving surface finish at the nano level is the biggest challenge to the industries because it is a time consuming and costly task [2]. A significant portion, about $15-20 \%$ of the cost product is spent on the finishing of the product. The overall production of the product is directly affected by the finishing time [3]. Various cylindrical parts are used i.e. shafts, spindles, automotive parts, punches, pins, plungers, valve and die industry, etc. in various machines and equipment, which requires a high finish surface.

There are many finishing processes are in industries to finish the external cylindrical surfaces. The mainly cylindrical grinding process is used to finish the external and internal cylindrical surfaces [4]. In the conventional 
grinding process, there is no control over the machining forces. The workpiece and grinding wheel directly contact and rubbing with each other due to this a large amount of heat is generated. Due to these reasons several defects i.e. microcracks, sub-surface defects, heat affected zone, thermal stresses, etc. are produced on the surface [5-6].

Industry and researchers develop various advanced processes to overcome these problems and enhance the characteristics of the surface of the product [7]. Among all these processes, magnetic assisted processes can finish the surface of the parts up to nano level without any defect [8]. In magnetic assisted processes the finishing forces are easily controlled by varying the current supply to the electromagnet coil or by changes the gap between the workpiece and the magnetic tool. Magnetic assisted finishing (MAF) process used to finish the flat, three dimensional (3D), internal and external cylindrical surfaces [9-13]. Ball end magnetorheological finishing process also developed to finish the flat and 3D shapes with more accuracy and precisely [14-15]. In all the magnetic assisted processes a smart fluid is used, which is called magnetorheological fluid. Magnetorheological fluid is prepared by mixing the abrasives particles, CIP's particles with the base fluid or carrier fluid [16]. Various fluid i.e. water, mineral oil, paraffin oil, grease, etc. are used as carrier fluid or base fluid. Additives and surfactants are also added to enhance the properties of the fluid, to prevent the sedimentation of the abrasive and iron particles $[17,18]$. The magnetorheological fluid changes its properties when the magnetic field applied to it. The iron particles in the fluid form the chains in the direction of the magnetic lines of forces and hold the abrasive particles between those chains and make a flexible brush, which behaves like a multiple cutting tool and helps to remove the material in the micro/tiny chips [19]. Due to flexibility and controllability, these types of processes can be used for any type of material [20].

The research work reported in this work has several limitations. In general, they focus on the magnetic abrasive finishing of external cylindrical surfaces, applicable only to hard materials. These systems are applicable only to single diameter cylindrical surfaces, i.e. tapered, grooved or stepped shafts cannot be finished. A turning type magnetorheological process has also been reported to finish external cylindrical surfaces on soft material [21]. However, this process applies only to a specified single diameter of the shaft, based on the tip of the tool. For finishing the shaft of a different diameter, a different tip of the tool is required.

To fulfil such a diversified need for finishing the external cylindrical surfaces, a rotating wheel type magnetorheological finishing process has been developed. The proposed finishing process is worked on the principle of the external cylindrical grinding machine. In the previous both setup the only workpiece is rotated and the magnetic tool in the stationary position. In this work, an electromagnet wheel is design which holds the magnetorheological fluid on its periphery while rotation. In this new process interaction increases between workpiece and electromagnet wheel because both are rotating. The proposed superfinishing process may be useful for finishing the external cylindrical, taper, stepped, or grooved surfaces with close tolerance and desired level of accuracy.

\section{MATERIAL AND METHOD}

The mild steel external cylindrical steeped shaft has been selected for the experimentation because, in large numbers of machines or mechanisms, mild steel cylindrical shafts are used. In various applications, shafts are supported by the bearings, nuts, or bushes. During the running condition, the shafts rotate between the bearings or bush supports. If the shaft is not properly aligned or not properly finished, the shaft cannot perform the function properly and may get damaged or wear by friction. To reduce friction and wear losses the shafts are required to finish properly. The composition of the mild material shaft is shown in Table 1. 
Table 1: Composition of the mild steel workpiece

\begin{tabular}{|c|c|}
\hline Element & Mass \% \\
\hline $\mathrm{Fe}$ & $98.1 \%$ \\
\hline $\mathrm{C}$ & $0.273 \%$ \\
\hline $\mathrm{Si}$ & $0.234 \%$ \\
\hline $\mathrm{Mn}$ & $0.560 \%$ \\
\hline $\mathrm{P}$ & $0.0415 \%$ \\
\hline $\mathrm{S}$ & $0.0749 \%$ \\
\hline $\mathrm{Ni}$ & $0.14 \%$ \\
\hline $\mathrm{Al}$ & $0.137 \%$ \\
\hline $\mathrm{Cu}$ & $0.16 \%$ \\
\hline
\end{tabular}

The experimentation is performed on the newly develop rotating wheel magnetorheological process. A photograph ofthe rotating wheel based magnetorheological process setup is shown in figure 1. The setup is installed on the HMT-22 lathe machine. Tool post of the machine removed and magnetorheological rotating wheel is attached on the cross slide with the help of fixture. Magnetorheological wheel's axis of rotation is aligned parallel to the axis of rotation of the workpiece. A DC motor with a RPM controller is also fixed on the fixture plate to rotate the newly design magnetorheological wheel. The rotation is given to the wheel with the pulley and belt arrangement. The present tool coil design is almost the same as the design of the BEMRF tool coil. The difference is that three electromagnet coils are used to make the wheel whereas only one electromagnet coil is used in the BEMRF tool. The three coils are placed at $120^{\circ}$ angles with each other so that they all make a circle. The circular arcs are also formed at the end of each coil to make a circular wheel. Detail drawing of electromagnet core and actual photograph of magnetorheological rotating wheel based tool is shown in figure 2. The current is given to the coils with the help of the regulated DC supply. The magnetic field strength at the wheel's periphery explicitly depends on the current supply supplied to the electromagnet coils. In this phase, the magnetic field has played a significant role because if the magnetic field is high then it helps maintain the magnetorheological fluid strongly on the wheel's periphery. The mild steel material (4000 relative permeability) is used as the central material of the electromagnet coil to get the maximum magnetic field because mild steel has good magnetic properties. The 19 gauge copper wire having relative permeability 0.999991 is select for the coiling of electromagnet coil. The tool has three coils, each coil has 1400 no. of turns. A gap is maintained between the workpiece and electromagnetic wheel with the help of so feeler gauge so that magnetorheological fluid is filled between this gap. The Magnetorheological fluid is prepared by mixing the $20 \%$ of CIP's particles (average particle size $23 \mu \mathrm{m}$ ), $20 \%$ of silicon carbide abrasive powder (800 mesh size), $60 \%$ of base-fluid (80\% of paraffin oil and $20 \%$ of AP3 grease). All the constituents are measured by volume concentration and the mixing of fluid is done with the stirring machine. The fluid is applied on the periphery of the wheel manually. The magnet field is generated when the direct current is given to the coils with the help of DC regulated supply. Due to the magnetic field, the CIP's particles form the stiffed chains and tightly grip abrasive articles. The material removal takes place because of rotation and relative movement between the workpiece and magnetorheological wheel. The magnetic flux intensity is measured by the Gauss meter, which is 0.12 tesla at the mid of the wheel at 0.15 tesla at the edges on the wheel at $3 \mathrm{~A}$ current supply to each coil of the electromagnet. The magnetic flux intensity at edges is more due to the edge effect. The initial and final surface roughness of the mild steel workpiece is measured with the Taylor Hobson's SURTRONIC 25 contact-type surface roughness tester. 


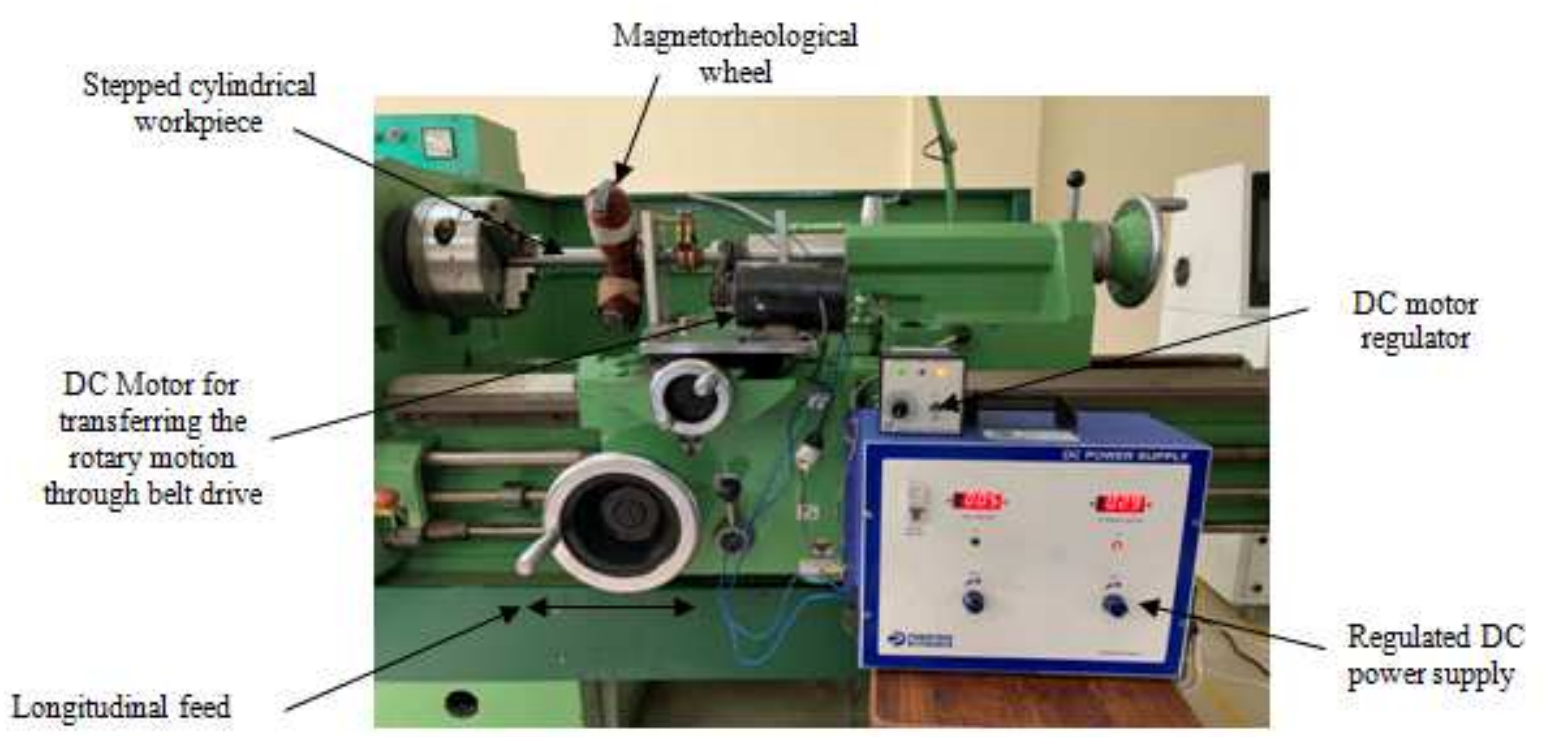

Figure 1: Photograph of rotating wheel based magnetorheological finishing setup

(a)

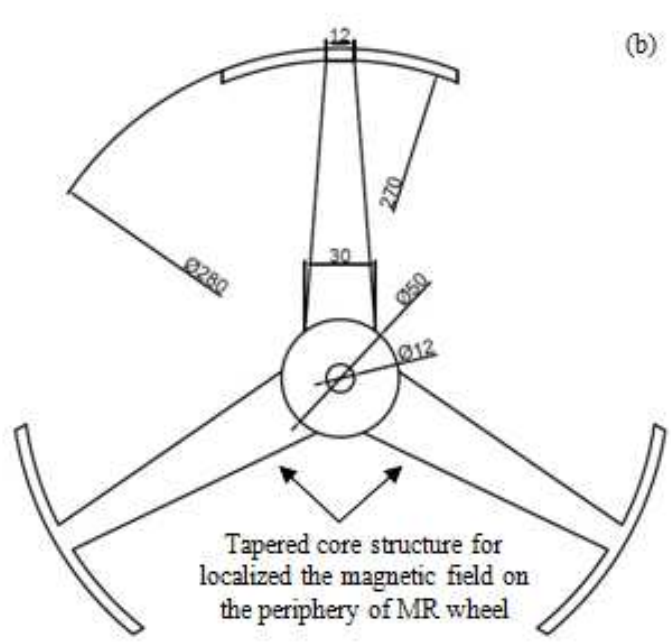

(b)

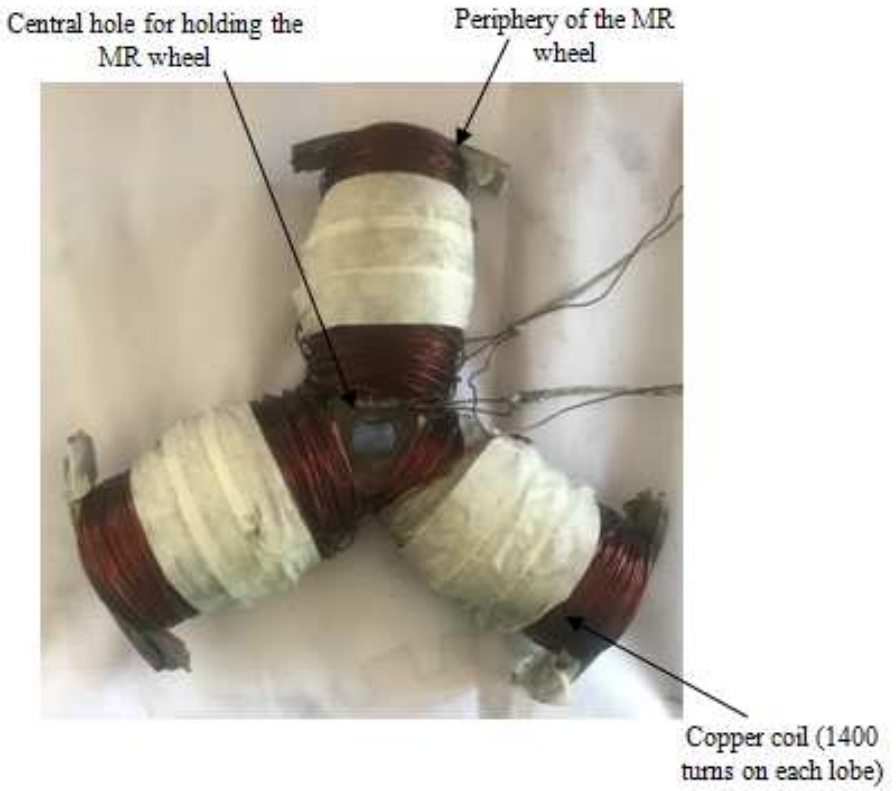

Figure 2: (a) Detail Drawing and (b) photograph of the electromagnet tool.

The material removal in this process is by shearing and abrasion. The abrasive particles are held between the CIP particle chains which are formed in the direction of the magnetic force lines. The CIP's particles mainly attract towards due to this indentation force particles are indented in the workpiece, whereas tangential force is generated by the relative motion between the workpiece and wheel. Both the indentation force and tangential force make a resultant force which helps to remove material from the workpiece. The gap is maintained between the workpiece and the magnetorheological rotating wheel is shown in figure 3(a) and figure 3(b) shows that the CIP's particles arrange in the direction of magnetic lines hold the abrasive particles and form a flexible brush. 


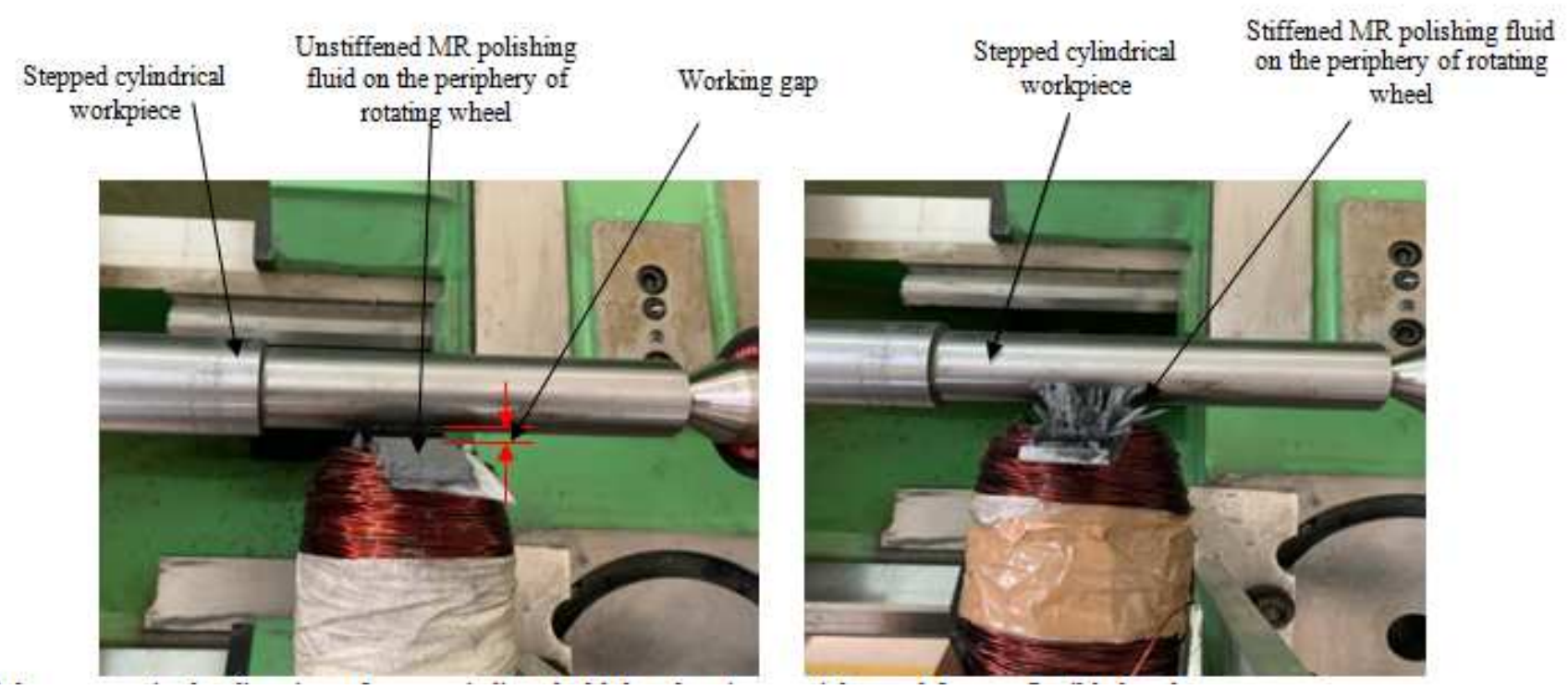

Figure 3: Photograph of (a) gap between the workpiece and magnetorheological rotating wheel and (b) MR fluid

form brushes in the presence of the magnetic field.

This process is newly developed so that there are no data available in the literature to decide the parameters. Various combinations of rotation ofthe workpiece and rotation of the magnetorheological wheel select to see the effect on surface roughness value during the trial experiments and noted that the lower speed of the workpiece and higher speed of the magnetorheological wheel gives the significant results. The best result found at the 200 RPM of the magnetorheological wheel if increases in the RPM more than 200 then the MR fluid starts loosen its grip due to the centrifugal force because increases in the rotation speed the centrifugal force is also increased. At lower speed, the process takes more time to finish the surface. The rotation speed of the workpiece is set at 40 RPM. After the large no. of trial experiments, the best results are found on parameters are given in Table 2.

Table 2: Experimental parameters and conditions

\begin{tabular}{|l|c|}
\hline \multicolumn{1}{|c|}{ Parameters } & Conditions \\
\hline Finishing cycle time (min) & 75 \\
\hline Magnetizing current (A) & 3 \\
\hline Rotational speed of tool (RPM) & 200 \\
\hline Rotation speed of workpiece (RPM) & 40 \\
\hline Magnetizing current (A) (each coil) & 3 \\
\hline Working gap (mm) & 0.6 \\
\hline Feed rate (mm/min) & 6.4 \\
\hline
\end{tabular}

\section{RESULTS AND DISCUSSIONS}

For finishing the mild steel external cylindrical surface workpiece, the newly designed magnetorheological rotating wheel setup is used. The material removal in the present due to the abrasion between the active abrasive particles and surface roughness peaks. The active abrasive particles are held by the iron particles chain structure. The edge effect phenomena help to localization of the magnetic field lines that improve the magnetic flux density over the tool periphery. This helps to hold the active abrasive particles strongly and help to shear off the roughness peaks. The average change in the surface roughness value $\mathrm{Ra}$ after each finishing cycle is reported in table 3 . The roughness of a workpiece is measured after every 25 minutes. The Ra value is changed from $0.52 \mu \mathrm{m}$ to $0.41 \mu \mathrm{m}$ in the first $25 \mathrm{~min}$. In the next 25 minutes, Ra value is 
reduced from $0.41 \mu \mathrm{m}$ to $0.35 \mu \mathrm{m}$.

Similarly, in the last cycle, the final measured $\mathrm{Ra}$ value is $0.31 \mu \mathrm{m}$ after the 75 minutes of machining. The surface roughness is not reduced the same in each cycle, this is because the shear modulus is higher at the bottom of the roughness peaks than the upper portion. The surface roughness profiles of before and after 75 minutes finishing are shown in figure 4.

The percentage change in roughness value is calculated from Eq. (1).

$\mathrm{Ra} \%=\left[\left(\mathrm{R}_{\mathrm{ai}}-\mathrm{R}_{\mathrm{af}}\right) / \mathrm{R}_{\mathrm{ai}}\right] * 100$

After 75 minutes of the finishing cycle, the wheel based magnetorheological finishing process reduced the value of $\mathrm{Ra}, \mathrm{Rq}, \mathrm{Rz}$ to $0.31,1.98,0.40 \mu \mathrm{m}$ from initial value $0.51,3.16,0.691 \mu \mathrm{m}$. It is observed that the roughness is initially reduced drastically than the later this is happening becausethe modulus of peaks is higher at the bottom as compared to the top of peaks. The surface roughness values $\mathrm{Ra}, \mathrm{Rq}, \mathrm{Rz}$ is reduced to $39.21 \%, 37.34 \%, 42.11 \%$ with 75 minutes of machining. The average change in the surface roughness value $\mathrm{Ra}$ after each finishing cycle is reported in table 3.

Table 3: Effect on roughness value with the finishing time

\begin{tabular}{|c|c|c|}
\hline Working cycle & Surface roughness of cylindrical workpiece $(\boldsymbol{\mu m})$ & \% change in surface roughness \\
\hline 0 & 0.52 & -- \\
\hline 25 & 0.41 & 21.15 \\
\hline 50 & 0.35 & 14.63 \\
\hline 75 & 0.31 & 11.42 \\
\hline
\end{tabular}

(a)

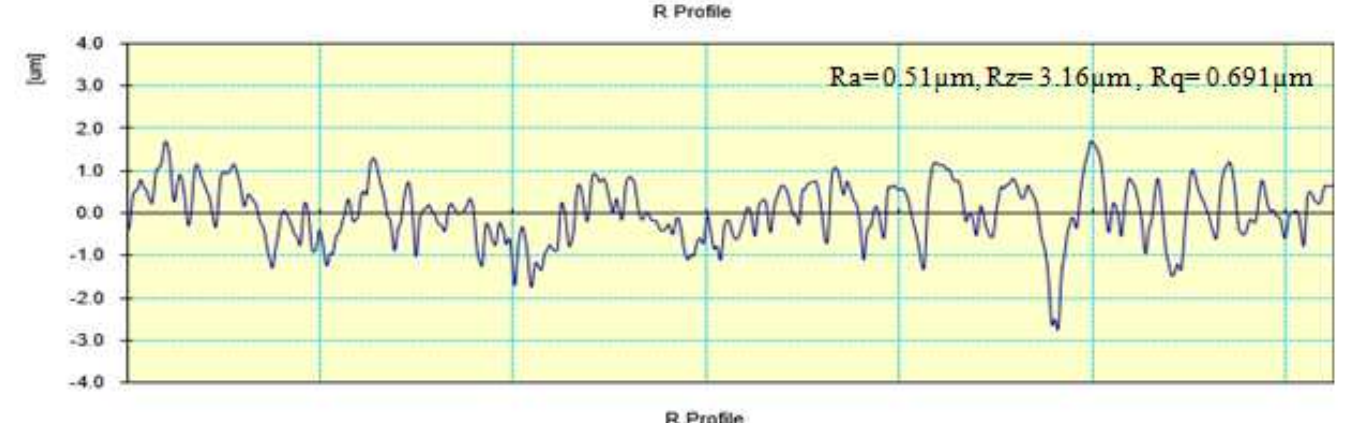

(b)

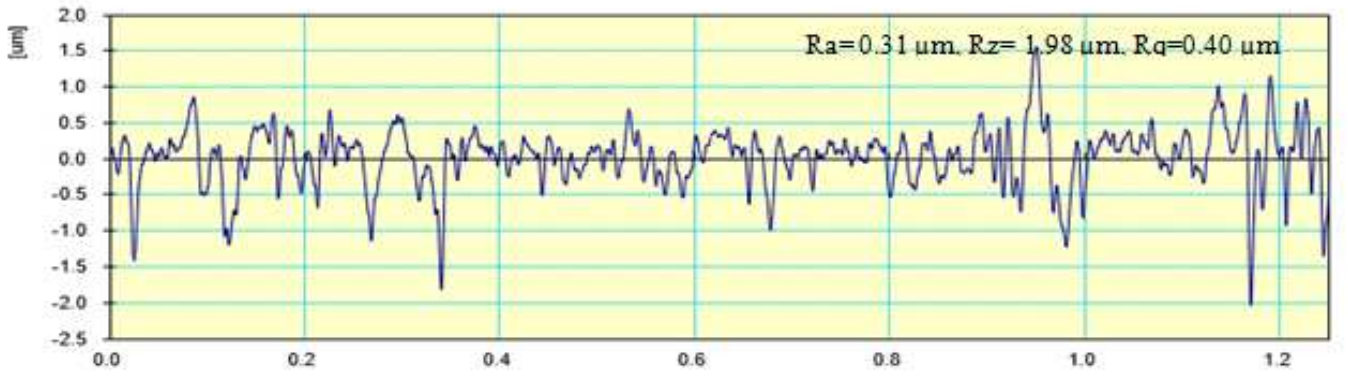

Figure 4: Roughness profiles of external circular surface of the mild steel workpiece (a) before and (b) after 75 minutes of finishing.

The mild steel shaft surface appearance is measured via the reflection check test. This test showsthe mild steel shaft surface presence before and after MR finishing. Figure 5 displays the translucent test images of the mild steel shaft's initial ground surface and MR finished surface, respectively. The text 'SLIET' is written on the white sheet for the reflection check and put in front of the mild steel shaft's external surface. Figure 5 indicates that, because of the grinding lies, the text ' SLIET ' is not visible at the initial ground level. But the grinding lays are extracted after the MR finishing 
and text ' SLIET ' is easily visible as depicted in Figure 5. From both test results, it is confirmed that the rotating wheel type Magnetorheological finishing setup can finish the external cylindrical surfaces. Therefore, the MR finishing of the exterior surface of the mild steel increases the surface consistency of the final products. The lower surface ruggedness improves the fit and tolerances. This helps to provide precise measurements of the products. MR finishing is also highly helpful in developing mild steel components practical capabilities in manufacturing industries.

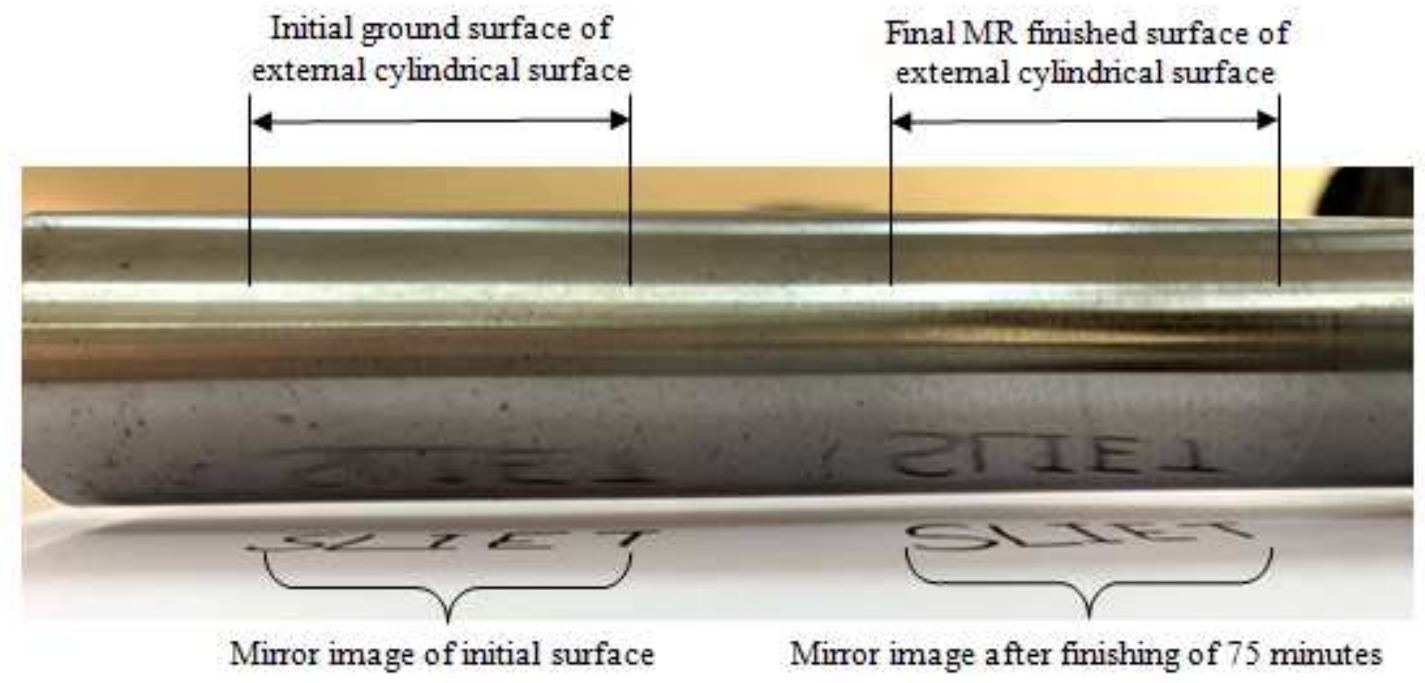

Figure 5:Mirror images on the external circular surface of the workpiece before and after 75 minutes of finishing.

\section{CONCLUSIONS}

The rotating wheel based Magnetorheological process is successfully developed for providing superfinishing operation to the external cylindrical surfaces. The following are conclusions are observed during the experimentation analysis.s

- The rotatingwheel based Magnetorheological finishing setup is designed and developed and it shows the feasibility and capability to provide a superfinishing operation to the external cylindrical surfaces.

- The average roughness of the mild steel external cylindrical workpiece after finishing operation has been reduced from $0.52 \mu \mathrm{m}$ to $0.31 \mu \mathrm{m}$ level in 75 minutes only.

- Surface roughness profiles and mirror image tests confirm the changes in roughness at the desired level successfully.

\section{REFERENCES}

1. Jain, V. K., Jayswal, S. C., \& Dixit, P. M. (2007). Modeling and simulation of surface roughness in magnetic abrasive finishing using non-uniform surface profiles. Materials and manufacturing processes, 22(2), 256-270.

2. Zhong, Z. W. (2008). Recent advances in polishing of advanced materials. Materials and Manufacturing Processes, 23(5), $449-456$.

3. MADURA, VIJAYA KUMAR, et al. "Design and experimental study of semi active system of MR damper for vibration control." International Journal of Mechanical and Production Engineering Research and Development 8.5 (2018): 125-132.

4. Jain, V. K. (2008). Abrasive-based nano-finishing techniques: an overview. Machining Science and Technology, 12(3), 257294. 
5. Lim, H. S., Fathima, K., Kumar, A. S., \& Rahman, M. (2002). A fundamental study on the mechanism of electrolytic in-process dressing (ELID) grinding. International Journal of Machine Tools and Manufacture, 42(8), 935-943.

6. Alonso, U., Ortega, N., Sanchez, J. A., Pombo, I., Izquierdo, B., \& Plaza, S. (2015). Hardness control of grind-hardening and finishing grinding by means of area-based specific energy. International Journal of Machine Tools and Manufacture, 88, 2433.

7. Liu, M., Nguyen, T., Zhang, L., Wu, Q., \& Sun, D. (2015). Effect of grinding-induced cyclic heating on the hardened layer generation in the plunge grinding of a cylindrical component. International Journal of Machine Tools and Manufacture, 89, 55-63.

8. Hashimoto, F., Yamaguchi, H., Krajnik, P., Wegener, K., Chaudhari, R., Hoffmeister, H. W., \&Kuster, F. (2016). Abrasive fine-finishing technology. CIRP Annals, 65(2), 597-620.

9. T DHAKULKAR, K. A. P. I. S. H., M. R. Dharme, and K. R. Gawande. "An experimental analysis of direct evaporative cooler by varying materials of cooling pad." International Journal of Mechanical \& Production Engineering Research \& Development 7 (2017): 585-590.

10. Jain, V. K. (2009). Magnetic field assisted abrasive based micro-/nano-finishing. Journal of Materials Processing Technology, 209(20), 6022-6038.

11. Judal, K. B., Yadava, V., \& Pathak, D. (2013). Experimental investigation of vibration assisted cylindrical-magnetic abrasive finishing of aluminum workpiece. Materials and Manufacturing Processes, 28(11), 1196-1202.

12. Sadiq, A., \&Shunmugam, M. S. (2009). Investigation into magnetorheological abrasive honing (MRAH). International Journal of Machine Tools and Manufacture, 49(7-8), 554-560.

13. Maurya, N., et al. "EFFECT OF NANOPARTICLES ON PERFORMANCE OF MAGNETO-RHEOLOGICAL FLUIDS IN VIBRATION SUPPRESSION."International Journal of Mechanical Engineering (IJME) 7. 5, Aug - Sep 2018; 1-10

14. Gheisari, R., Ghasemi, A. A., Jafarkarimi, M., \&Mohtaram, S. (2014). Experimental studies on the ultra-precision finishing of cylindrical surfaces using magnetorheological finishing process. Production \& Manufacturing Research, 2(1), 550-557.

15. Nahi, A. M., \&Khadum, A. H., (2019). A review on Magnetic Abrasive Finishing Process for Finishing a Workpiece Surface. Test Engineering \& Management, 81(Non/Dec 19), 4258-4265.

16. Singh, A. K., Jha, S., \& Pandey, P. M. (2012). Magnetorheological ball end finishing process. Materials and Manufacturing Processes, 27(4), 389-394.

17. Singh, A. K., Jha, S., \& Pandey, P. M. (2012). Nanofinishing of a typical 3D ferromagnetic workpiece using ball end magnetorheological finishing process. International Journal of Machine Tools and Manufacture, 63, 21-31.

18. VERMA, PRIYA, NITIN NAIYAR, and SHRIKANT B. BURJE. "REVIEW OF BRAIN TUMOR DETECTION USING MR IMAGES. "International Journal of Electrical and Electronics Engineering Research (IJEEER) 7. 4, Aug 2017, 9-20

19. Saraswathamma, K., Jha, S., \& Rao, P. V. (2015). Experimental investigation into ball end magnetorheological finishing of silicon. Precision Engineering, 42, 218-223.

20. Bedi, T. S., \& Singh, A. K. (2018). A new magnetorheological finishing process for ferromagnetic cylindrical honed surfaces. Materials and Manufacturing Processes, 33(11), 1141-1149.

21. Kordonski, W., Gorodkin, S., \&Behlok, R. (2015). In-line monitoring of (MR) fluid properties. Journal of Magnetism and Magnetic Materials, 382, 328-334. 
22. Singh, A. K., Jha, S., \& Pandey, P. M. (2015). Performance analysis of ball end magnetorheological finishing process with MR polishing fluid. Materials and Manufacturing Processes, 30(12), 1482-1489.

23. Fei, C., Zuzhi, T., \& Xiangfan, W. (2015). Novel process to prepare high-performance magnetorheological fluid based on surfactants compounding. Materials and Manufacturing Processes, 30(2), 210-215.

24. Niranjan, M., Jha, S., \&Kotnala, R. K. (2014). Ball end magnetorheological finishing using bidisperse magnetorheological polishing fluid. Materials and Manufacturing Processes, 29(4), 487-492.

25. Singh, G., Singh, A. K., \& Garg, P. (2017). Development of magnetorheological finishing process for external cylindrical surfaces. Materials and Manufacturing Processes, 32(5), 581-588. 

